\title{
Increased prolactin response to thyrotropin releasing hormone during migraine attacks
}

\author{
Y PAPAKOSTAS, M DARAS, M MARKIANOS, C STEFANIS \\ From the Department of Psychiatry, Athens University Medical School, Eginition Hospital, and the Neurology \\ Department of the Evagelismos Hospital, Athens, Greece
}

SUMMARY Prolactin (PRL) has been associated with the pathogenesis of migraine, and various approaches have been used to investigate its role. In the present study, the PRL response to thyrotropin-releasing hormone (TRH) was evaluated in eight women migraineurs during an attackfree state and during a migraine attack. PRL baseline values were not different in the two states, and the same was true for the TSH responses to TRH. The PRL responses to TRH were, however, significantly higher during the attack, a finding that indicates a latent disturbance of the PRLregulating systems in migraine, with a higher responsiveness during migraine attacks.

Increased levels of plasma prolactin (PRL) found in some conditions associated with migraine attacks (stress, exercise, use of oral contraceptives), and the PRL suppressing effect of some anti-migraine drugs (ergot alkaloids, clonidine), are observations that support the notion that PRL is involved in the mechanism of migraine pathogenesis. ${ }^{12}$ Certain studies, however, failed to demonstrate a PRL involvement, ${ }^{3-6}$ while others, using the levodopa inhibiting test, showed some abnormalities in the PRL secretion mechanisms in migraine. ${ }^{7-9}$ In the present study, we investigated the PRL response to thyrotropin-releasing-hormone (TRH) in female patients suffering from migraine, in the intervals between attacks and during an attack.

\section{Patients and methods}

Eight women suffering from migraine, 28 to 46 years of age (mean 35.7), were evaluated. According to the criteria defined by the "Ad Hoc Committee on Classification of Headache", ${ }^{10}$ six suffered from common and two from classical migraine. Patients with a history of a significant head

Address for reprint requests: Dr Y Papakostas, Athens University Medical School Psychiatric Clinic, Eginition Hospital, Vass. Sophias 74, Athens 11528, Greece.

Received 22 July 1986 and in revised form 21 October 1986. Accepted 28 November 1986 injury within the last year or evidence of endocrine abnormalities were excluded. All patients were free of drugs during the 2 weeks before testing, and were found normal in a systematic physical and neurological examination. Their EEGs and CTs of the head were also normal. They all had a formal psychiatric examination, and the Hamilton Depression Scale $^{11}$ was completed. No evidence of depression or other significant psychiatric disturbance was found.

The first TRH test was performed during an attack free interval. The patient was then instructed to come during an attack to have the test repeated, if the attack occurred during the morning hours. The TRH test was thus always performed between 0800 and 1200 hours, with the patient recumbent. Blood samples were drawn through an indwelling catheter that was kept patent with slow infusion of normal saline. After the first blood sample was obtained (time 0 ) $0.4 \mathrm{mg}$ TRH were given IV as a bolus and samples were further obtained at 20,40 and 60 minutes. Plasma was separated by centrifugation and kept at $-30^{\circ} \mathrm{C}$ until estimation. PRL levels were assayed by radioimmunoassay techniques (Biodata kit) and the results expressed in $\mathrm{ng} / \mathrm{ml}$. $1 \mathrm{ng}$ corresponds to $23 \mu \mathrm{IU}$ of the WHO 75/504 International Reference Preparation.

For the statistical evaluation of the data the Wilcoxon test for pair differences and the Spearman correlation coefficient were used.

\section{Results and discussion}

The individual plasma PRL levels of the eight patients during the two TRH tests are shown in the table. 
Table Individual values of plasma prolactin levels $(\mathrm{ng} / \mathrm{ml})$ in 8 migraine patients during the TRH-test, performed during an attack-free period $(A F)$ and during a migraine attack $(M A)$. The difference in maximal $P R L$ response between the two states is significant (Wilcoxon test, $2 a<0.02$ )

\begin{tabular}{|c|c|c|c|c|c|c|c|c|c|c|}
\hline \multirow[b]{2}{*}{$N r$} & \multicolumn{4}{|c|}{ Attack-free period } & \multicolumn{4}{|c|}{ During attack } & \multicolumn{2}{|c|}{ Max. response } \\
\hline & $0^{\prime}$ & $20^{\prime}$ & $40^{\prime}$ & $60^{\prime}$ & $0^{\prime}$ & $20^{\prime}$ & $40^{\prime}$ & $60^{\prime}$ & $A F$ & $M A$ \\
\hline $\begin{array}{l}1 \\
2 \\
3 \\
4 \\
5 \\
6 \\
7 \\
8\end{array}$ & $\begin{array}{r}16.7 \\
11 \cdot 4 \\
22.8 \\
12.1 \\
8.5 \\
12.5 \\
9.2 \\
21 \cdot 1\end{array}$ & $\begin{array}{r}37 \cdot 4 \\
83 \cdot 0 \\
31 \cdot 2 \\
48 \cdot 5 \\
47 \cdot 9 \\
27 \cdot 2 \\
55 \cdot 5 \\
104 \cdot 1\end{array}$ & $\begin{array}{l}31 \cdot 7 \\
82 \cdot 6 \\
27 \cdot 2 \\
37 \cdot 7 \\
23 \cdot 5 \\
22 \cdot 4 \\
49 \cdot 2 \\
90 \cdot 2\end{array}$ & $\begin{array}{l}28 \cdot 3 \\
45 \cdot 7 \\
24 \cdot 2 \\
23 \cdot 9 \\
17 \cdot 9 \\
19 \cdot 5 \\
34 \cdot 1 \\
75 \cdot 3\end{array}$ & $\begin{array}{r}11 \cdot 1 \\
19 \cdot 5 \\
22.7 \\
17 \cdot 0 \\
8.4 \\
12.8 \\
7.3 \\
8.6\end{array}$ & $\begin{array}{r}46 \cdot 3 \\
102 \cdot 8 \\
42 \cdot 5 \\
59 \cdot 5 \\
68 \cdot 2 \\
26 \cdot 7 \\
88 \cdot 5 \\
101 \cdot 6\end{array}$ & $\begin{array}{l}38.7 \\
91 \cdot 4 \\
40 \cdot 8 \\
53 \cdot 8 \\
39.2 \\
24.6 \\
73.9 \\
85 \cdot 1\end{array}$ & $\begin{array}{l}22 \cdot 5 \\
74 \cdot 4 \\
33 \cdot 4 \\
32 \cdot 2 \\
30 \cdot 8 \\
23 \cdot 3 \\
54 \cdot 7 \\
79 \cdot 2\end{array}$ & $\begin{array}{r}20 \cdot 7 \\
71 \cdot 6 \\
8.4 \\
36 \cdot 4 \\
39 \cdot 4 \\
14 \cdot 7 \\
46 \cdot 3 \\
83 \cdot 0\end{array}$ & $\begin{array}{l}35 \cdot 2 \\
83 \cdot 3 \\
19 \cdot 8 \\
42 \cdot 5 \\
59 \cdot 8 \\
13 \cdot 9 \\
81 \cdot 2 \\
93 \cdot 0\end{array}$ \\
\hline $\begin{array}{l}\text { mean } \\
\text { S.D. }\end{array}$ & $\begin{array}{r}14.3 \\
5.4\end{array}$ & & & & $\begin{array}{r}13.4 \\
5.7\end{array}$ & & & & $\begin{array}{l}40 \cdot 1 \\
26 \cdot 5\end{array}$ & $\begin{array}{l}53.6 \\
30.3\end{array}$ \\
\hline
\end{tabular}

The baseline PRL levels for the group were not different between the attack free period and during migraine attack. However, the PRL responses to TRH (maximal post-TRH value minus baseline value) were higher during the attack $(2 \mathrm{a}<0.02$, Wilcoxon test), while there were no differences in the TSH responses to TRH. The TSH response was blunted (less than $5 \mu \mathrm{U} / \mathrm{ml}$ ) in three cases during the attack free period and remained blunted in two and normalised in one case during the attack. No significant relationships (Spearman correlation coefficient) were found between PRL response and factors like age, weight, or TSH response.

Several studies, ${ }^{7-9}$ which used the levodopa inhibiting test, have demonstrated an abnormality in PRL secretion in migraine sufferers. Our findings of higher PRL response to TRH during the migraine attack than during an attack free period indicate an hyperactivity of the PRL secreting mechanisms during the attack. Since baseline PRL levels of our patients were similar in both states, this higher PRL response is not likely to be due to non-specific factors such as stress or pain.

Serotoninergic hyperactivity and dopaminergic deficiency are the two main proposals for understanding the pathogenesis of migraine on the neurotransmitter level. ${ }^{12-14}$ Our data fit well to such hypothesis. The facts that baseline PRL levels of our patients were similar in both states and that only the PRL, and not the TSH response to TRH was different during the attack, favour an increased readiness of the PRL release promoting system, that is, an altered (enhanced) sensitivity of serotoninergic receptors, whose effect on PRL release during the test cannot be controlled by the dopaminergic system. This, however, cannot be but an oversimplification, since many factors take part in the regulation of PRL secretion ${ }^{15}$ and interactions of more than one factor are expected to cause the abnormality of PRL secretion in migraine.

\section{References}

1 Horrobin DF. Annual Research Reviews, Prolactin. Montreal: Eden Press, 1975:134-50.

2 Horrobin DF. Annual Research Reviews, Prolactin. Montreal: Eden Press, 1976:155-6.

3 Nader S, Tulloch B, Blair C, Vydelingum N. Is prolactin involved in precipitating migraine? Lancet 1974;ii: 17-19.

4 Epstein MT, Hockaday JM, Hockaday TDR. Migraine and reproductive hormones throughout the menstrual cycle. Lancet 1975;i:543-8.

5 Polleri A, Nappi G, Maturzo P, et al. Neuroendocrine approach to headache. Adv Neurol 1982;33:173-82.

6 Dorow R, Horowski R, Graef K-J. The role of prolactin in migraine. Acta Endocrinol Scand 1983;suppl.102: 36-37.

7 Vardi J, Flechter S, Ayalon D, Cordova T, Oberman Z. L-Dopa effect on prolactin plasma levels in complicated and common migrainous patients. Headache 1981;21:14-20.

8 D'Andrea G, Cnanzi AR, Soffiati G, Cortesi S, FerroMilone F. Tuberoinfundibular dopaminergic transmission in children migraine. Cephalalgia 1985; 5(suppl.3):106-8.

9 Nattero G, Corno M, Savi L, Isaia GC, Priolo C, Mussetta M. Prolactin and migraine: Effect of L-Dopa on plasma prolactin levels in migraineurs and normals. Headache 1986;26:9-12.

10 Ad Hoc Committee on Classification of Headache. JAMA 1962;179:127-8.

11 Hamilton M. A rating scale for depression. J Neurol Neurosurg Psychiatry 1960;23:56-62.

12 Sicuteri F, Fanciullaci M, Anselmi B. The serotonin (5-HT) theory of migraine. Adv Neurol 1974;4:383-93.

13 Sicuteri F. Dopamine; the second putative protagonist in headache. Headache 1977;17:129-31.

14 Fanciullacci M, Michelacci S, Curradi C, Sicuteri F Hyperresponsiveness of migraine patients to the hypotensive action of bromocriptine. Headache 1980 20:99-102.

15 Leong DA, Frawley LS, Neill JD. Neuroendocrine control of prolactin secretion. Ann Rev Physiol 1983; 45:109-27. 